\title{
Avaliação de uma intervenção educativa na prevenção da dengue
}

\author{
Evaluation of an educative intervention \\ to prevent dengue
}

Rejane Cristina Brassolatti 1

Carlos Fernando S. Andrade 2

\begin{abstract}
The aim of the present study was to evaluate an educative approach for dengue prevention in Campinas, SP, Brazil. The approach was based on a 20-hour course for fundamental school teachers, their subsequent work upon the students, and from the students to their relatives. In the course it was supplyied didactic matherial, matherial for mosquito identification and traps for surveillance. Three biological agents were supplied for demonstrations and use as control agents against traped mosquitoes. It was evaluated the reduction or elimination of dengue vector breeding sites for the school environment and for a sample of student dwelling, up to one year after the course. It was observed an expected increase of knowledgment but a less significative increase of school environments free from potential mosquito breeding sites.
\end{abstract}

Key words Dengue, Education, Aedes aegypti
Resumo 0 objetivo do presente trabalho foi o de avaliar uma abordagem educativa para a prevenção da dengue em Campinas. A abordagem foi baseada em um curso de 20 horas para professores de ensino fundamental, seu subseqüente trabalho com os alunos, e destes para seus familiares. No curso foram fornecidos instrumentos didáticos, para a identificação de mosquitos e armadil lhas para vigilância. Foram fornecidos três agentes biológicos para demonstrações e uso, como agentes de control e de mosquitos capturados nas armadilhas. Foi avaliada a redução ou eliminação de sítios de criação dos vetores da dengue para os ambientes escolares e para uma amostra das residências dos estudantes, até um ano depois do curso. Foi observado um esperado aumento do conhecimento, mas um aumento menos significativo nos ambientes escolares livres de sítios potenciais de criação do mosquito.

Palavras-chave D engue, Educação, Aedes aegypti

\footnotetext{
1 Departamento

de M edicina Preventiva

e Social, Faculdade

de Ciências M édicas da

Universidade de Campinas.

Cidade Universitária

Zeferino Vaz, 13081-970

Campinas SP.

rejanecristina@uol.com.br

2 Instituto de Biologia,

Universidade de Campinas.
} 


\section{Introdução}

A situação do Brasil em relação à dengue e ao risco de reurbanização da febre amarela tem se agravado cada vez mais nos últimos anos. Essa situação constitui-se, igualmente, num dos mais importantes problemas de saúde pública em vários outros países, exigindo avanços na busca de soluções e obtenção de resultados satisfatórios nos programas de controle dos vetores. Em todo o mundo, um dos pontos-chave destes programas, e dos mais difíceis de se obter sucesso, éaquele relativo ao papel das comunidades, eliminando, e não permitindo a produção do vetor em criadouros domésticos. Um controle mecânico, do ponto de vista da entomologia aplicada e do manejo integrado de vetores, cuja chave está no controle social. Os mosquitos mais visados nessas ações são o Aedes aegypti e o Aedes albopictus.

As formas tradicionais de controle de mosquitos têm fortes limitações no ambiente urbano. 0 controle químico, por exemplo, tem sido em geral associado a problemas como o desenvolvimento de resistência, agressão ao ambiente eà saúde da população, e, pior, costuma causar uma errônea impressão de que poderia resolver sozinho a questão do controle, atenuando, com isso, o papel das outras formas. Lamentavelmente, levou-se cerca de 20 anos para se constatar que as aplicações de U Itra Baixo Volume (UBV) tinham na verdade pouca ou nenhuma eficiência no controle das epidemias de dengue (Gubler, 1989). 0 controle biológico do mosquito vetor da dengue, por sua vez, embora possa ser eficiente eatrativo como alternativa ao controle químico, na grande maioria das vezes depende das pessoas para introduzirem os agentes nos potenciais criadouros (Andrade, 1998). No ambiente doméstico, os criadouros são em geral descartáveis (como pneus velhos e latas) ou solucionáveis ( como caixas d'água destampadas e calhas entupidas), ou mesmo evitáveis (como vasos de plantas com água e pratos de xaxins). Em todos os países, são muitas as intervenções educativas voltadas para os problemas de saúde pública, mas pouco ou quase nada tem sido feito para uma avaliação desses processos educativos, buscando-se identificar o resultado final, o grau de eficácia de diferentes medidas, as fal has ou as dificuldades dessas intervenções.

Para al gumas arboviroses, cujo controle dos vetores pode ser feito através da participação efetiva da população, é fundamental que o obje- tivo entomológico seja muito bem conhecido pelas comunidades (Reiter, 1992). Assim, no caso da dengue, a educação deve ter como objetivo uma eliminação mensurável de criadouros dos mosquitos vetores no ambiente doméstico, pelo cidadão, e não simplesmente 0 acréscimo de conhecimento. E assim, o parâmetro de avaliação desses trabalhos deve ser entomológico, e não estritamente educacional. Os trabal hos educativos convencionais nessa área têm sido 0 da veiculação pela mídia, outdoors, faixas, painéis, cartazes, folhetos, ou palestras em escolas e outros núcleos sociais. As principais deficiências são: a) tem sido definido um nível de conhecimento ideal e tenta-se passá-lo para a população, supondo que uma vez adquirido implicará mudança de hábitos, b) depois de realizados, esses trabal hos educativos consideram que foram efetivos no controle de criadouros do vetor, sem, no entanto, apresentar resultados entomológicos, como ocorreu, por exemplo, na Índia (Yadava \& Narasimham, 1990) ou no Brasil (Passos et al., 1998).

Quando lançado pelo governo brasileiro em 1996, o Plano Nacional de Erradicação do Aedes aegypti (PNEAa) não deu ênfase à educação e à participação da comunidade na eliminação de criadouros, mas sim à erradicação do mosquito vetor em um típico sistema "de cima para baixo" (Gubler, 1989). De acordo com Krogstad \& Ruebush (1996), entretanto, devido à necessi dade de programas econômicos e sustentáveis para a prevenção e controle de doenças em países tropicais, seria exatamente a participação da comunidade a melhor intervenção ou estratégia. Embora nos últimos anos as atividades de informação, educação ecultura (IEC) tenham sido mais bem contempladas dentro do PNEAa, nunca ficou muito claro para a comunidade que havia um objetivo entomológico a ser conquistado no ambiente doméstico, e que deveria ser de um número de criadouros potenciais igual a zero.

A escola é ponto de partida eficiente para a educação voltada à saúde pública, envolvendo diversas questões como, por exemplo, a dengue (Andrade, 1998), helmintíases (M ello et al., 1995; Santos et al., 1993) ou a pediculose, particularmente geral e muito freqüente no meio escolar (M adureira, 1992). As crianças, e especialmente as estudantes, formam classicamente um excelente canal para a introdução de novos conceitos na comunidade, pelo fato de serem membros permanentes desta, e por estarem com o cognitivo em formação. Segundo Regis et 
al. (1996), a escola mostrou-se um espaço privilegiado para a obtenção do envolvimento da população do Recife no controle da filariose, pela sua representatividade (representantes da maioria das famílias do bairro); por ser um assunto que oferece excelente material didático para diferentes abordagens; pela oportunidade de aproximação de um problema existente na comunidade; pelas mudanças de atitudes que devem ocorrer mais facilmente em crianças e também pela incorporação do tema ao conteúdo programático e sua reprodução nos anos subseqüentes. No entanto, a condição de carência da educação em nosso país élamentavelmente um fato. E essas deficiências, principalmente no que dizem respeito às escolas públicas, relacionam-se em geral à falta de instrumentalização do professor e à falta de informações.

0 presente trabal ho visou avaliar uma intervenção educativa baseada em um treinamento forte de professores, para servirem de multiplicadores aos al unos e colegas, e auxiliarem, por meio de uma vigilância entomológica no ambiente da escola, na prevenção da dengue nesse espaço e, por extensão, na comunidade. Esse trabalho foi feito para os professores e escolas municipais de ensino fundamental de Campinas.

\section{Metodologia}

0 presente estudo focalizou os participantes de um curso (Educação para o M anejo Integrado dos Vetores da Dengue - 97; Extecamp, U nicamp) com duração de 20 horas, em cinco dias, oferecido à Prefeitura Municipal de Campinas. Foram treinados 46 participantes em duas turmas, 39 deles professores de ensino médio e fundamental, uma coordenadora da área pedagógica da Secretaria M unicipal de Educação e seis funcionários municipais da área da saúde (dois deles também professores).

O curso pressupôs informar, formar, treinar, instrumentalizar e estimular esses educadores a atuarem como multiplicadores junto aos seus colegas, aos al unos e, por extensão, à comunidade. Além de aprenderem sobre os vetores da dengue e aspectos da doença em aulas teórico-práticas ministradas na universidade, todos os participantes receberam um kit com material para trabal har com os alunos e para o trabalho de vigilância dos vetores da dengue em suas respectivas escolas e locais de trabal ho. Esse kit foi composto de quatro bandejas plásti- cas $(30 \times 40 \mathrm{~cm})$, uma caixa de madeira (20x30x $10 \mathrm{~cm})$, um laminário com lâminas permanentes de larvas de 40 estádio de Aedes aegypti, Aedes al bopictus e Culex quinquefasciatus, lâminas e lamínulas, uma pipeta Pasteur, três tetinas para pipeta (látex), dois pincéis $n^{\circ} 2$, um microscópio de bolso com iluminação à pilha (aumento 8x e 30x), cinco frascos transparentes ( $2 \mathrm{~cm}$ diâmetro $\times 6 \mathrm{~cm}$ altura) com tampa, etiquetas, álcool 70\%, ovos e larvas de mosquitos respectivamente preservados a seco e em álcool 70\%, e adultos de Aedes albopictus, Aedes aegypti $\mathrm{e} C \mathrm{x}$. quinquefasciatus montados em alfinete entomológico. Como material impresso os professores receberam um manual ilustrado contendo exercícios (Andrade et al., 1997) e transparências para aulas e exposições sobre a dengue e o manejo de mosquitos. Para o trabaIho de vigilância semanal nas escolas e para o controle biológico dos vetores receberam duas armadilhas na forma de uma seção de $1 / 3$ de pneu de motocicleta com alça e etiquetas grandes (tamanho A4) em acetato. Receberam uma criação inicial de dois agentes de controle biológico, a planária Girardia tigrina e o copépodo M esocyclops Iongi setus, e ainda placas de petri com cultura de Bacillus thuringiensis var. israe lensis (Bti) além de um frasco contendo a bactéria na forma de produto comercial (VECTOBAC, Abbott, Laboratório do Brasil) para demonstrações do controle microbiano dos pernilongos. Receberam também uma prancha com fotos coloridas sobre os sintomas da dengue e dengue hemorrágica em crianças (foto de pessoas doentes) e uma figura com os típicos criadouros do mosquito vetor, além de uma pasta com recortes deartigos enotícias de jornais e revistas sobre a questão dengue.

O grupo participante dos professores, uma amostra de seus alunos e parte da comunidade de relação desses professores foram avaliados, antes a após esse trabalho educativo, por um período de um ano. As avaliações constaram de questionários, entrevistas e visitas às respectivas escolas onde lecionava cada professor participante etambém às moradias da amostra de alunos, para observação do ambiente escolar e doméstico, quanto à existência e cuidados com criadouros potenciais dos vetores da dengue.

\section{Resultados}

$\mathrm{Na}$ avaliação escrita prévia com os participantes do curso, a totalidade mencionou que já ti- 
nha informações sobre a dengue, pela televisão e jornais. A maioria dos participantes $(55,8 \%)$ respondeu que não sabia reconhecer o mosquito vetor Aedes aegypti adulto e quem respondeu afirmativamente, 52,6\% não o descreveu de maneira correta. 0 restante $(47,4 \%)$ 0 fez de forma apenas parcialmente correta, não havendo, portanto, nenhuma descrição completamente correta do vetor, nem mesmo por parte dos agentes de saúde partici pantes. Como critério considerou-se que tal descrição deveria mencionar pelo menos os aspectos: pernilongo pequeno, cor escura (ou preto), manchas claras ou brancas nas patas e no corpo e hábitos diurnos. Esperava-se a menção de que a espécie Aedes aegypti se distingue por possuir um desenho em forma de lira no dorso do tórax.

A maioria absoluta dos participantes $(97,7 \%)$ apontou o não acúmulo de água em recipientes domésticos como a melhor atitude que poderia ser tomada para evitar a proliferação dos vetores da dengue. Houve apenas $7 \%$ de menção ao processo educativo como medida importante, embora estivessem, no momento do teste, iniciando um curso com esse pressuposto.

Dos professores participantes, $61,5 \%$ afirmaram que ainda não tinham trabalhado a questão dengue com os al unos devido à "falta de material informativo" e 46,2\% indicaram ainda a "falta de motivação e/ou estímulo" para esse fim.

Na prova de avaliação final, no último dia do curso, os participantes obtiveram $100 \%$ de acerto em questões que se referiam ao controle da dengue, sintomas e o desenvolvimento da doença, possíveis criadouros do vetor e sua eliminação. Também mostraram $97,8 \%$ de acerto na descrição diferencial de adultos dos mosquitos A edes aegypti, Aedes albopictus e Culex quinquefasciatus, e $63 \%$ de acerto na prova prática, baseada na diferenciação de larvas dessas espécies a partir do uso de seus próprios microscópios de bolso.

Em 11 questões da prova teórica referentes à biologia do mosquito vetor da dengue, emedidas a serem tomadas quanto ao controledo mesmo, a porcentagem de acertos foi sempre superior a $90 \%$.

$N$ as avaliações com os professores um e dois meses após o curso, buscou-se visitar 14 escolas das quais fazem parte os 16 professores da amostra tomada. Não foi possível a visita à escola de dois desses professores. Em uma delas por motivo de afastamento da professora que seria entrevistada e na outra por impedi- mento da direção da escola, que alegou saber muito pouco sobre o projeto.

As demais avaliações ocorreram oito e doze meses após o curso, com todos os professores participantes. Os resultados quanto às atividades desenvolvidas por eles nas escolas nesses períodos estão nas figuras 1,2 e 3.

Após o início do trabalho proposto no curso, $68,8 \%$ dos professores entrevistados afirmaram ter melhorado a situação de suas escolas quanto à existência de potenciais criadouros do mosquito da dengue, e 43,8\% afirmaram ter coletado larvas de Aedes em suas armadilhas. Toda a ocorrência de mosquitos foi na armadilha de vigilância, enão naquela com os agentes de controle biológico. E 85,7\% das larvas foram identificadas como Aedes aegypti.

Dos 14 professores visitados na primeira avaliação, todos afirmaram ter envolvido alunos no trabalho sobre a dengue; $42,8 \%$ envolveram também outros professores; e 37,5\% envolveram funcionários da escola, como vigilantes e serventes.

No item O bservações \& Dificuldades solicitado no questionário aos professoresum mês após o curso, o que eles mais citaram foi a insegurança com os cuidados adequados à manutenção dos predadores planárias e copépodos (Figura 4).

Também foram entrevistados 70 alunos desses professores na primeira avaliação, um

\section{Figura 1}

Evolução das atividades de informação desenvolvidas pelos professores participantes, após 1, 2, 8 e 12 meses da realização do curso Educação eM anejo Integrado dos Vetores da Dengue

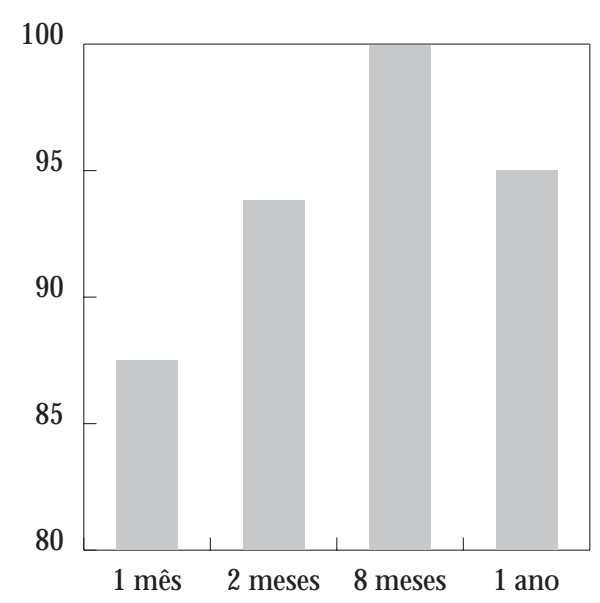




\section{Figura 2}

Evolução das atividades de trabalho com as armadilhas, desenvolvidas pelos professores participantes, após 1, 2, 8 e 12 meses da real ização do curso Educação e $M$ anejo Integrado dos Vetores da Dengue

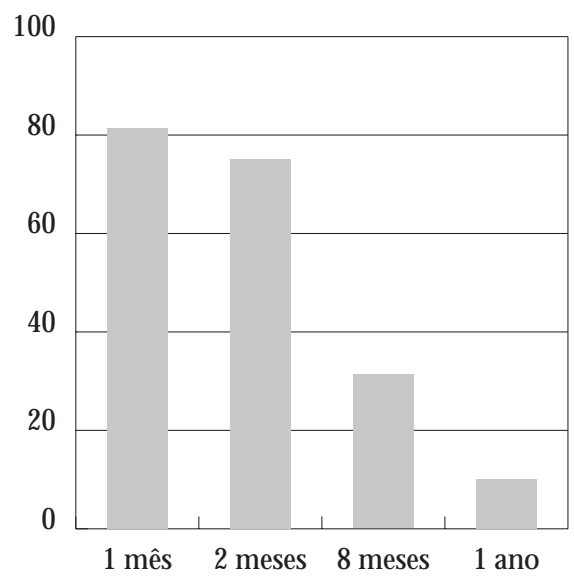

mês após o curso, sendo a maioria (42,9\%) alunos de 5 à à 8a séries. Desses alunos entrevistados, 97,1\% confirmaram que no último mês a questão dengue havia si do trabalhada na escola pelos professores participantes do curso, com atividades de informação, trabalho semanal com as armadilhas e atividades de controle.

A grande mai oria dos alunos entrevistados $(84,3 \%)$ já tinha ouvido falar sobre a dengue (57,6\% através da TV). Segundo 32,2\% deles, a mensagem "não servira para mudar nenhum hábito", ou ainda, segundo 30,5\% dos entrevistados, os hábitos "só foram alterados na época em que ouviram falar do problema".

Dos alunos entrevistados nessa primeira avaliação, 44,3\% sabiam que a dengue é causada por um vírus e $57,1 \%$ souberam dizer que étransmitida pelo mosquito de nome Aedes aegypti. A grande maioria (90\%) afirmou que a dengue é uma doença grave, mas só $17,1 \%$ justificaram essa resposta afirmando que é uma doença que pode causar hemorragia. D esses alunos avaliados, 74,3\% afirmaram que evitariam a dengue não deixando água parada em qualquer recipiente; e 94\% afirmaram que ensinam o que aprenderam sobre a doença para outras pessoas eavaliam que praticamente a metade $(47,1 \%)$ ouve e muda seus hábitos em função do que eles falam.

Nessa fase, também foram visitadas 24 residências de alunos para entrevistas, sendo que

\section{Figura 3}

Evolução das atividades de controle de criadouros nas escolas, desenvolvidas pelos professores participantes, após 1, 2, 8 e 12 meses da realização do curso Educação e $M$ anejo Integrado dos Vetores da Dengue

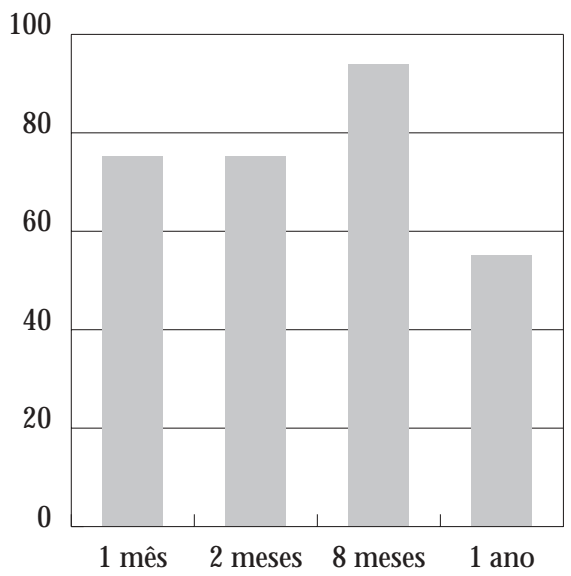

$75 \%$ dos familiares entrevistados afirmaram que estavam recebendo informações sobre a dengue através da criança, como não deixar água parada para não criar o mosquito. Das famílias entrevistadas, 79,2\% indicaram que não deixar água parada é uma atitude que se deve tomar para o controle da dengue; e 50\% afirmaram que aprenderam o que sabem sobre a dengue com as informações trazidas da escola pelo aluno.

Dois meses após o curso, em nova avaliação com os professores, a metade deles classificou como "médio" o grau de dificuldade para a implantação do projeto na escola, apontando como maiores problemas a depredação das armadilhas instaladas e a falta de cooperação das demais pessoas da comunidade escolar (Tabela 1).

A avaliação dos primeiros três meses após o curso mostrou que a maioria dos professores passou a envolver os alunose, em menor grau, os funcionários e outros professores da escola no trabal ho com a dengue.

Após oito meses do curso, os professores foram novamente avaliados. Quanto ao trabalho com as criações dos agentes predadores, houve um interesse muito grande por permitir o uso de seres vivos como instrumento em aulas. A maioria dos professores dessa amostra pretendia continuar o trabalho proposto, utilizando as informações e materiais recebidos, assim como 


\section{Figura 4 \\ Freqüência das dificuldades apontadas pelos professores avaliados no trabalho em suas escolas, um mês após a realização do curso Educação e M anejo Integrado dos Vetores da Dengue}

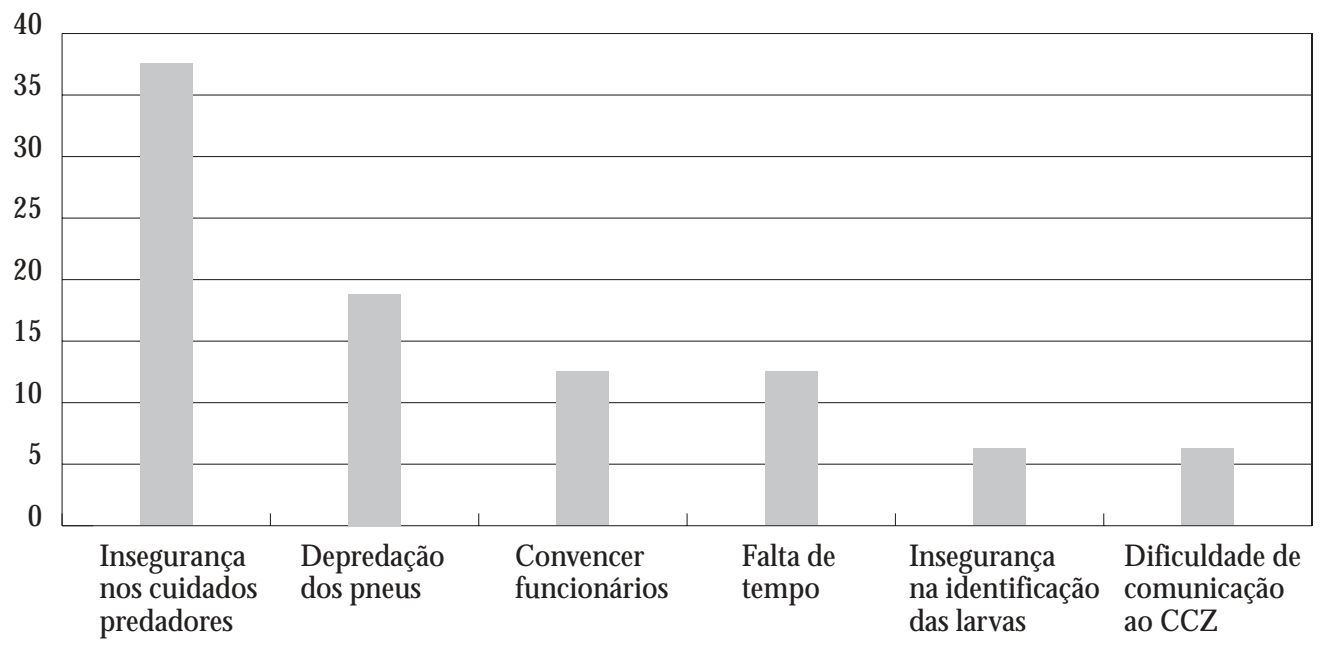

\section{Tabela 1}

Freqüência das dificuldades apontadas pelos professores quanto à implantação do projeto dengue nas escolas, dois meses após o curso

\begin{tabular}{lc}
\hline Respostas dos professores avaliados & $\%$ \\
\hline Depredação das armadilhas & $31,2 \%$ \\
Falta de cooperação de colegas, & \\
funcionários e direção & $31,2 \%$ \\
Outras & $25,0 \%$ \\
Falta de tempo & $18,7 \%$ \\
Manutenção dos predadores & $18,7 \%$ \\
Falta de local adequado para & $18,7 \%$ \\
as armadilhas & $6,3 \%$ \\
Nenhuma dificuldade; não respondeu & \\
\hline
\end{tabular}

a grande maioria afirmou continuar com o controle de criadouros em suas casas, na escola e na casa de seus familiares. A maioria afirmou também que seus alunos continuavam ainda muito envolvidos com a questão dengue, pelo fato de demonstrarem uma mobilização quanto ao controle de possíveis criadouros, e mobilizarem também seus familiares a fazerem o mesmo. Essa informação foi dada aos professores, principalmente pelos pais desses alunos, nas reuniões escolares.
Um ano após o curso, observou-se que esses professores ainda tratavam o assunto dengue em aulas expositivas, insistindo com os alunos sobre os cuidados em relação ao controle de criadouros. Quanto ao trabalho de vigilância e controle biológico, a grande maioria desses professores (90\%) havia interrompido. Em relação ao controle de criadouros a maioria afirmou que continuava a fazer nas escolas ( $50 \%$ ), nas próprias residências ( $100 \%$ ) e nas de amigos e parentes (55\%) que freqüentam.

Quanto às escolas visitadas no final de um ano de avaliação, num total de 20 , em $55 \%$ delas não havia nenhum criadouro potencial para 0 mosquito vetor da dengue, sendo que tal situação, segundo os professores, foi devida ao trabalho de conscientização realizado por eles. Em $45 \%$ das escolas visitadas ainda havia recipientes que poderiam se tornar criadouros, como vasos com água, pratos sob vasos de plantas e alguns entulhos. A grande maioria (mais de $90 \%$ ) dos alunos desses professores que passaram pelo curso sobre a dengue continuou envolvida com a questão após um ano da realização do mesmo einício do trabalho pelos professores nas escolas. Os próprios alunos atuavam na eliminação de criadouros em suas residências e/ou insistiam com o controle de criadouros junto às suas famílias. As avaliações com es- 
ses al unos mostraram, um ano após o curso, que $55,8 \%$ deles afirmaram terem tentado convencer também seus parentes a tomarem cuidado com água parada; $18,2 \%$ citaram também vizinhos; e 45,5\% afirmaram que não tinham atuado nesse sentido com relação a outras pessoas que não as de sua família direta (pais e irmãos).

De todos os alunos entrevistados, 54,4\% afirmaram que em suas casas ainda havia potenciais criadouros para o mosquito vetor, como pratos sob vasos (a maioria), vasos com água, tambores descobertos e plantas em vasos com água.

\section{D iscussões e conclusões}

Na avaliação prévia, a referência ao processo educativo pelos professores participantes como medida importante no controle dos vetores da dengue teve um percentual muito baixo (7\%), indicando uma falta de percepção desses professores de que a educação, e conseqüente mudança de hábitos, poderia ser muito importante para se evitarem criadouros do mosquito da dengue. Essa visão foi sensivelmente alterada ao final do curso.

$\mathrm{Na}$ avaliação ao final do curso, o percentual de descrição correta dos mosquitos adultos aumentou para quase $100 \%$, e, em geral, os participantes foram capazes de identificar também as larvas das três espécies em lâminas a fresco que eles próprios fizeram. Um excelente resultado quando comparado com a avaliação prévia. Essa tarefa exigiu o uso do microscópio integrante do kit, para a observação de características como o pecten do 8 o segmento e os espinhos meso e meta torácicos nas larvas, e o padrão de escamas nos mosquitos adultos.

No acompanhamento feito com os professores participantes no decorrer do ano de avaliação, a maior dificuldade apontada em relação ao trabalho desenvolvido nas escolas foi quanto à vigilância e ao controle biológico. Problemas de depredação das armadilhas e perda das criações dos predadores foram os mais citados. No entanto, notou-se também uma falta ou incapacidade de dedicação dos professores em cuidar das criações dos predadores (apesar de uma de suas maiores queixas ser a falta de material para aulas práticas e do grande entusiasmo que demonstraram no curso). Embora a universidade tenha se comprometido a auxiliar os participantes na criação dos predadores e a fazer eventuais reposições, a procura foi pequena, ficando abaixo de $10 \%$. N otou-se, por- tanto, que esses educadores e agentes de saúde não tiveram um envolvimento mais profundo e a dedicação necessária a uma estratégia apontada por eles próprios como eficiente e desejável. Os professores al egaram como determinantes disso a falta de colaboração dos demais funcionários (principalmente da direção), e a instabilidade funcional, situação particular naquele ano quando houve muitas demissões, transferências entre escolas e mudança na administração municipal.

Quando questionada, a maioria dos professores cujas escolas tinham potenciais criadouros do mosquito vetor da dengue alegou que tais criadouros eram semanalmente vistoriados e limpos de qualquer resíduo de água. Outras alegações foram a resistência de funcionários da escola em se livrarem de tais objetos, assim como a não-cooperação da direção da escola, que não via potencial perigo nos mesmos.

Quanto aos alunos, as avaliações mostraram que a criança, quando entende realmente a seriedade da questão, é atuante, persistente, coerente e ousada na responsabilidade atribuída. No entanto, na avaliação após um ano, mais da metade declarou que em suas casas ainda havia criadouros, e a maioria reproduziu a explicação da família (geralmente a mãe) de que esses criadouros "são cuidados e vistoriados quase diariamente", acreditando, assim, estar prevenindo a produção de larvas.

Esses resultad os de certa forma revertem a expectativa de que as crianças poderiam produzir comportamentos mais adequados aos objetivos entomológicos. Sabe-se que na maioria das vezes esses potenciais criadouros não são na verdade vistoriados com tanta regularidade quanto se declara, tornando-se importantes focos do vetor Aedes aegypti (Leontsini et al., 1992). De fato, essa é uma questão crítica na prevenção da dengue. 0 governo não pode cuidar de todo criadouro doméstico e não conseguiu ainda convencer o munícipe a fazê-lo. Esse problema é até certo ponto derivado dos programas "de cima para baixo", nos quais a administração pública chama para si a responsabilidade do controle, e a comunidade se torna passiva. De forma análoga, os pais, usando de sua autoridade, assumem o cuidado e passam a impressão para a criança de que estão atendendo a seus apelos na forma de um maior cuidado com os potenciais criadouros, tranqüilizando-a, então.

Os resultados indicam que o trabalho educativo com professores possibilitou em parte a di- 
minuição de risco de transmissão nas escolas, pela eliminação de criadouros observada. $\mathrm{Na}$ época de pico de transmissão da dengue na região sudeste do Brasil (meses de fevereiro a maio), as crianças passam grande parte do dia no espaço escolar, e, portanto, tal ambiente necessita obviamente especial cuidado, como foi também verificado por Yongyuth (1992) em escolas na Tailândia.

O curso possibilitou aos professores participantes um maior aprofundamento e esclarecimento com relação à questão da dengue, assim como outras alternativas pedagógicas de trabaIho com os alunos, além das clássicas pesquisas escritas e cartazes, o que eles estavam habituados a fazer. Os professores se sentiram mais seguros e instrumentalizados para trabalhar a questão com os alunos. Os alunos, por sua vez, se mostraram bastante estimulados com o trabalho desenvolvido nas escolas, principalmente com as atividades que envolveram as armadi lhas de vigilância, a identificação das larvas coletadas e a eliminação de potenciais criadouros na escola, em suas casas e outros locais por eles fre qüentados. A maioria desses alunos tentou convencer suas famílias a mudarem seus hábitos quanto ao acúmulo de água em recipientes domésticos. Essa atitude de insistência e persistência foi confirmada por muitos pais nas reuniões escolares, porém apenas uma fração dessas famílias $(20,8 \%)$ alterou realmente seus hábitos, eliminando ( $12,5 \%$ ) ou diminuindo $(8,3 \%)$ o número de possíveis criadouros do mosquito vetor da dengue em suas residências, conforme verificado nas visitas.

O bservou-se que o processo educativo e de mudança de atitudes foi evoluindo ao longo do período de avaliação de um ano, podendo-se afirmar que em $55 \%$ das escolas visitadas houve aumento do grau de proteção das crianças e demais pessoas, por não mais existirem criadouros potenciais para o mosquito.

0 mesmo ocorreu em relação às residências dos alunos desses professores. 0 número de re sidências sem criadouros aumentou em cerca de $12 \%$ no primeiro trimestre de avaliação e para $41 \%$ após um ano, demonstrando um aumento gradativo de proteção com relação ao vetor da doença. Deve-se lembrar, no entanto, que o município passou por uma epidemia de dengue no verão de 1998, o que seguramente também contribuiu para a mobilização das pessoas.

Dentro de uma reflexão final, cabe salientar que, de maneira geral, no Brasil, as autoridades não têm definido claramente os objetivos em relação à dengue, ou aos mosquitos vetores $\mathrm{e}$ seus criadou ros. E, obviamente, para cada situação específica há uma lógica relação entre empenho (mesmo financeiro) e objetivos. Como exemplo, enquanto os municípios do sul do Texas, nos Estados Unidos, se empenham em não ter o vetor e, conseqüentemente, nenhum caso da dengue clássica, o objetivo em Porto Rico já se resume a ter poucos casos da forma hemorrágica. E pior ainda, escolas da Tailândia desenvolvem um programa para a redução da mortalidade escolar infantil pela doença. 0 noticiário de jornal sobre a dengue tem mudado bastante no Estado de São Paulo nos últimos anos. Inicialmente apenas referindo-se aos números de novos casos ou suspeitos nos municípios, hoje as notícias são sobre punições (auditorias federais, multas, Comissões Parlamentares de Inquérito) ou prêmios (cestas básicas, televisores ou bilhetes de loteria), um claro indicador de que estão sendo necessários reforços ao processo de envolvimento social. M as falta serem avaliados. E falta a proposição clara do que se pretende como objetivo em relação à dengue. 


\section{Referências bibliográficas}

Andrade CSF, Brassolatti RC \& Santos LU 1997. Educação para o manejo integrado dos vetores da dengue. M anual U NICAM P. Campinas, 36pp.

Andrade CSF 1998. Uma educação especial para o controle biológico dos vetores da dengue. Anais do VI Siconbiol - Simpósio de Controle Biológico. Rio de Janeiro, p. 156.

Gubler DJ 1989. Aedes aegypti and Aedes aegypti - borne disease control in 1990s: top down or bottom up. American Journal Tropical. M edical Hygien 40:571-578.

Krogstad DJ \& Ruebush II TK 1996. Community Participation in the Control of Tropical Diseases. Acta Tropica 61:77-78.

Leontsini E, Gil E, Kendall C \& Clark GG 1992. Effect of a community - based Aedes aegypti Control Programme on M osquito Larval Production Sites in El Progreso, Honduras, pp. 265-277. In S. B. Halstead \& GomezDantes (eds.). Proceedings of the International Conference on D engue and Aedes aegypti Community Based Control.

M adureira PR 1992. Aspectos epidemiológicos do Pediculus capitis. Estudo entre préescolares de Paulínia. Tese de doutorado. Faculdade de Ciências M édicas da UNICAM P, 128pp.

M ello DA, M artins CB, Bittencourt Jr AC, M atos RM C, Pina F, M iranda ZA 1995. Pesquisa participante na intervenção da transmissão de helmintoses intestinais (cidade satélite do Paranoá - Distrito Federal). Revista da Sociedade Brasileira de M edicina Tropical 28(3):223-232.
Passos ADC, Rodrigues EM S \& Dal-Fabro AL 1998. Dengue Control in Ribeirão Preto, São Paulo, Brasil. Cadernos de Saúde Pública 14 (suplemento 2):123-128.

Regis $L$ et al. 1996. Integrated control of the filariasis vector with community participation in na urban area of Recife, Pernambuco, Brazil. Cadernos de Saúde Pública 12(4):473-82.

Reiter $\mathrm{P}$ 1992. Status of Current Aedes aegypti Control Methodologies, pp. 41-48 In SB H alstead \& GomezDantes (eds.). Proceedings of the International Conference on Dengue and Aedes aegypti Community Based Control I.

Santos M G, M oreira M M , M alaquias M LG \& Schall V 1993. Educação em saúde em escolas públicas de 10 grau da periferia de Belo Horizonte, M G, Brasil. II Conhecimento, opiniões e prevalência de helmintíases entre alunos e professores. Revista Instituto de M edicina Tropical 35(6):573-579.

Yadava RL \& Narasimham M VVL 1990. Epidemiology and control of dengue and dengue hemorrágica fever in India. Southeast Asian Journal Tropical M edicine Public Health 21(4):683.

Yongyuth W 1992. Dengue Hemorrhagic Fever Control in Thailand. In SB Halstead \& Gomez-Dantes (eds.). Proceedings of the International Conference on Dengue and Aedes aegypti Community - based Control, IV: 161-167.

Artigo apresentado em 15/12/2001

Versão final apresentada em 12/1/2002

Aprovado em 12/3/2002 